\title{
Loss of Control, Attributions, and Helplessness in the Homeless
}

Shawn M. Burn

Control has emerged as an important psychological variable. The purpose of this project was to extend the concept of environmental control to the homeless shelter environment. Data from interviews conducted with residents of a homeless shelter supported the hypothesis that perceived loss of control over the shelter environment would be positively related to giving up on finding a home and employment. The hypothesis that the helplessness created by low control environments is consistent with the external, stable attributional style of "universal" helplessness was partially supported. Suggestions for future research are provided. Changes in the shelter environment are recommended for the treatment of helplessness in the homeless though helplessness is expected to persist as long as poverty, expensive housing, and prejudice against the homeless make efforts and outcomes noncontingent.

With an estimated 200,000 to three million homeless in the United States (Redburn \& Buss, 1986), it is evident that homelessness is a serious social problem. This paper describes a survey research study conducted with homeless individuals. The purpose of the project was to extend the concept of environmental control (i.e., perceived control over the environment) and the consequences of loss of control to the homeless shelter environment. In addition, the project was intended to examine the role of low-control environments in the creation of "universal helplessness." This type of learned helplessness occurs when the individual makes an external attribution for the lack of contingency between his or her behavior and outcomes (Abramson, Garber, \& Seligman, 1980). Environments over which occupants have little control were expected to lead to external attributions and a decreased motivation to respond.

\section{Distinguishing between Personal and Universal Helplessness}

The relationship between perceptions of control and passivity has received attention from both clinical and environmental/ social psychologists. Clinical psychologists Abramson, Seligman, and Teasdale (1978) describe the explanatory style of the depressed patient and how it leads to passivity. Such patients tend to make internal, stable, and global attributions for negative life events ("it's me, it's going to last forever, and it's going to affect everything in my life"). Abramson et al. (1978) call this type of helplessness "personal helplessness."

Abramson et al. (1978) acknowledge that external attributions for negative life events ("I can't control these outcomes but it's not my fault") may also lead to helplessness as long the individual feels that outcomes are independent of his or her responses. They call this type of helplessness "universal helplessness." The main difference as they see it is that self-esteem loss and depression are more likely when an internal attribution for noncontingency is made (since the implication is that the individual is personally responsible for the noncontingency).

Although not explicitly identified as "universal" helplessness, a large body of work in environmental psychology has focused on the environment's role in creating control expectations and how environments low in control may lead to passivity. The environment shapes such expectations by 
limiting the types of choices and range of options available to the user (Proshansky, Ittelson, \& Rivlin, 1970).

Research by environmental psychologists (Baum \& Paulus, 1987; Cohen, Evans, Stokols, \& Krantz, 1986) and other psychologists (Dweck \& Repucci, 1973; Hanusa \& Schulz, 1977; Rodin, 1976;

Wortman, Panciera, Shuster-man, \& Hibscher, 1976) has provided support for the hypothesis that individuals exposed to uncontrollable sources of environmental stress suffer from helplessness (universal helplessness) and that such individuals are inclined to make external attributions for this lack of control (Baum \& Gatchel, 1980, described in Baum, Gatchel, Aiello, \& Thompson, 1981; Dweck \& Repucci, 1973; Hanusa \& Schulz, 1977; Wortman, et al., 1976).

The distinction between "personal" and "universal" helplessness is important because they have different treatment implications, one calling for intervention at the individual, cognitive level, and the other at the environmental level. Research by Dweck and Goetz (1978) and Dweck and Licht (1980) suggests, for example, that those with a depressive explanatory style (personal helplessness) were exposed to authority figures in childhood who attributed the child's failures to internal, stable causes such as lack of ability. In such cases, cognitive therapies such as those developed by Beck (Beck, Rush, Shaw, \& Emery, 1979) may be necessary to change the internal control beliefs of the individual. However, cognitive therapies are unlikely to work for individuals who are in environments where what happens to them truly has little to do with their efforts. To intervene in these cases, environments should be designed and organized to provide individuals with increased control. Langer and Rodin (1976) provided retirement home residents with control over day-to-day events which affected them, and found that residents provided with such control were happier, more alert, and more active than the comparison group. Environments which are high in occupant control may also prevent the negative control expectancies which tend to lead to helplessness in the first place and are "economical" in the sense that individual-by-individual treatment is not required.

\section{Passivity in the Homeless as Universal Helplessness}

Much of the passivity exhibited by homeless people may be the result of exposure to low-control environments. Most non-mentally ill homeless people come from low-income backgrounds where they have had to deal with many uncontrollable stressors such as noise, pollution, high density, crime, and government bureaucracy. As homeless people their efforts to obtain affordable housing are thwarted because of the requirement that they put up first and last months' rent and a security deposit before rental can take place, poor availability of low-income housing, and landlord reluctance to rent to homeless people. The perception of noncontingency between the homeless person's behavior and outcomes may be further aggravated by the shelter environment, an environment intended to help the homeless person.

Because the home is a primary territory where people can express themselves freely, and normally recover from the everyday hassles of life, its loss implies a loss of control over personal activities. The design of the typical shelter environment further exaggerates this loss. According to Altman (1975), primary territories such as homes promote privacy and, more than virtually any other environment, allow us to regulate our contact with others. Altman and Chemers (1980) suggest that a person who is unable to regulate open/ closedness is also unable to develop a competence at controlling life events. 
"Without the capacity to regulate our contact with others, no human being can survive psychologically or perhaps physically" (Altman \& Chemers, 1980, p. 83). In the shelter environment, as many people as possible are housed in a limited amount of space, making it hard for homeless individuals to regulate others' access to them. Privacy is also lost when admittance and continued residence in the shelter require the sharing of very personal information with shelter personnel. Help agencies and organizations further reduce the homeless individual's control by the imposition of curfews and rigid rules surrounding meals and sleeptimes, shelter arrival and departure times and acceptable daily activities.

In summary, by restricting the behavioral options and privacy of shelter residents, the shelter environment may exacerbate passive behavior. When the low-control shelter environment is combined with a lack of affordable housing and lack of jobs that pay a living wage, homeless people may come to perceive that what happens to them is not contingent upon what they do. Seeing that other homeless people are in essentially the same situation, they are probably inclined to make an external attribution for this lack of control. Thus it is likely that they experience "universal" rather than "personal" helplessness.

The study described below used face-to-face interviews conducted with homeless individuals at a homeless shelter. The following hypotheses were examined:

1. It was expected that high ratings on loss of privacy, feeling crowded, having little choice about where and when to sleep and eat would be correlated with giving up on finding a home and a job.

2. It was hypothesized that an external, stable attributional style would be positively correlated with giving up on finding a home and a job. This was expected because external, stable attributions imply that the individual's behavior is unlikely to be efficacious.

3. It was expected that perceptions of the shelter as being low in occupant control (low privacy, lack of choice about when and where to sleep and eat, etc.) would be positively correlated with the external, stable attributional style. (Low control environments probably lead to "universal" as opposed to "personal" helplessness.)

4. It was hypothesized that individuals who had a history of depression prior to homelessness would be more likely to exhibit the internal, stable, global attributional style characteristic of personal helplessness than those residents who reported no prior history of depression.

\section{Method}

\section{Respondents}

Forty-two homeless individuals staying at a major shelter in Southern California's Pomona Valley served as voluntary participants in the study. Respondents were paid $\$ 5.00$. Only those potential residents who exhibited no outward signs of mental illness were selected by the shelter's director for admittance.

The shelter housed ten adults for a period of 30 days. Respondents were required to leave the shelter by 8 a.m. and to return between 5:30 and 6 p.m. Shelter residents were required to cook and clean and 
demonstrate their efforts to find jobs and housing. Those who did not conform to these and other shelter rules were evicted.

Respondents ranged in length of time homeless from 2 days to approximately 2 years and 6 months. Eleven (26\%) of the respondents were male, 31 (74\%) were female (a greater number of females were admitted into the shelter, preference being given to families). Seventy percent of the respondents had children with them at the shelter. Age ranged from 20 to 60 with a mean of 33. Ethnicity varied also: 36\% were white; 54\% African-American; and 7\% were Hispanic (the remainder declined to answer this question). Most respondents had completed high school (63\%). Approximately 30\% had taken some college classes with only $2 \%$ completing a degree. For many respondents (38\%) Aid to Families with Dependent Children (AFDC) was the primary source of income; $12 \%$ worked; and $50 \%$ had no income at all. Respondents' mean income was $\$ 605.04$ a month.

\section{Interview Questions}

Helplessness/passivity. Helplessness/passivity was measured by asking extent of agreement (strongly agree, agree, agree a little, neutral, disagree a little, disagree, strongly disagree) with the following questions (respondents were shown a card with response options):

1. I feel it is no use trying to find housing I can afford.

2. I have given up trying to find a job.

3. I feel that if I try hard enough, I will find a place to live (scoring was reversed).

4. I have tried hard to find a place to live but it is no use.

An index was created by summing Likert responses to these statements. The standardized Cronbach's alpha for this index was .79.

Depression. Depression was measured by the Beck Depression Inventory (Beck \& Beck, 1972). This instrument consists of 21 items, each with four statements that vary in affect (e.g., "I do not feel sad," to "I am so sad or unhappy I can't stand it"). The statement least indicative of depression receives a score of 0 , the statement most indicative, a 3 . Numbers were then summed to provide an index of depression. These statements were read aloud by the interviewer and respondents were instructed to pick out the one statement in each group that best described the way that he or she had been feeling in the last week.

To differentiate between respondents who were depressed because of their homelessness and those who were depressed prior to losing their homes and possibly clinically depressed, respondents were asked extent of agreement (using a 7-point Likert scale) with the following statement: "I had problems with depression before losing my home."

Explanatory style. Explanatory style was measured using the majority of items from the Attributional Style Questionnaire (ASQ) developed by Peterson and Villanova (1988). The ASQ has the respondent give reasons for various negative life events and rate them on internality, stability, and globality. The original questionnaire consists of 24 questions and is a written instrument filled out by the respondent. For the purposes of the present study, nine items referring to events unlikely to be within the experience of respondents (e.g., "After your first term of school, you are on academic probation") and one item leading to respondent discomfort during pretesting ("You experience sexual difficulties") were excluded. An additional item measuring attributions for homelessness was added. Due to concerns about literacy, 
the adapted instrument was administered verbally by the researcher. Ratings for each dimension (internality, stability, globality) were then averaged to produce a mean internality, stability, and globality score for each respondent.

Control. Respondents rated the shelter on the amount of control experienced. The statements were selected to reflect areas over which individuals normally have control in primary environments. Extent of agreement (strongly agree, agree, agree a little, neutral, disagree a little, disagree, strongly disagree) with the following was asked:

1. I have no choice about when I eat.

2. I have no choice about where I sleep.

3. I have no choice about when I sleep.

4. I feel crowded at the shelter.

5. I have a lot of privacy here at the shelter.

6. I have a lot of freedom here at the shelter. (Scoring was reversed for the last two items).

An index of control was created by summing the 7-point Likert responses to these six items where higher numbers indicated greater agreement. Cronbach's standardized item alpha for this index was .73. Procedure

Face-to-face confidential interviews (1 to 2 hours each) were conducted on most Fridays from 7 to 9 p.m. beginning in January 1989 through July 1989. Although refusals were unusual, some residents were visiting nonresidents or working during interview times and were unable to be interviewed. Others were asked to leave the shelter because of rule violations or left the shelter without explanation and prior to participation in the study. Specific numbers on the incidence of such occurrences are unavailable.

The researcher would arrive and interview whomever had not been interviewed. Convenience of the residents (affected by childcare or chores) dictated which individuals were interviewed when. An effort was made to find a relatively private location where the respondent would feel free to talk. After the first few weeks, the researcher's presence on Friday nights was expected and understood by residents.

The researcher began the interview by explaining that she was a psychologist interested in the psychological consequences of homelessness. Respondents were told that all responses were confidential and would not be shared with shelter personnel, and that they would receive $\$ 5.00$ for participating; all that was asked in return was that they answer the questions honestly. It was also explained that the interview could be terminated at any time without loss of the $\$ 5.00$.

\section{Results}

\section{Hypothesis 1}

Correlations between control items (privacy, freedom, choice about when to eat, and where and when to sleep) and helplessness items are reported in Table I.

Results supported the hypothesis that perceived loss of control over the shelter environment would be positively correlated with helplessness. In other words, individuals whose ratings were high on perceived loss of privacy, feeling crowded, having no choice about where and when to sleep and eat, 
and feeling that there was little freedom at the shelter were more likely to feel helpless - that their actions would make little difference in obtaining employment or housing. The control index (a summed index of responses to all six control items) was significantly correlated with three of the four helplessness items and with the helplessness index (a summed index of the four helplessness items).

Feeling crowded, a lack of privacy, and low freedom were the strongest predictors of giving up on finding a place to live. Perceived lack of privacy was significantly correlated with the three items suggesting that efforts to find a home would be fruitless, crowding was significantly correlated with two, and lack of freedom with one. These three variables (privacy, freedom, and crowding) were all significantly positively correlated with the helplessness index. Agreement with the statement "I have no choice about when I eat" was significantly correlated with only one of the four helplessness items, "I feel it's no use trying to find housing I can afford." The perception of having no choice about when to sleep at the shelter was not significantly correlated with any of the helplessness items. Perceiving little choice about where to sleep at the shelter was significantly correlated with only one helplessness item, "I have tried hard to find a place to live but it's no use."

The perception of low freedom at the shelter was the only one of the six control items to be significantly correlated with giving up on trying to find a job. However, the control index (a summed index of responses to the six control items) was significantly correlated with giving up on finding a job.

\section{Hypothesis 2}

It was hypothesized that external, stable attributions would be positively correlated with helplessness because they imply that the individual's attempts to change things are unlikely to make a difference. The results provide limited support for this hypothesis. The correlation between external attributions for negative life situations and agreement with statements saying that the respondent had given up trying to find a job or housing approached significance $(r=-.25, p=.07)$. This was probably due to the significant correlation between externality and agreement with the statement "I have tried hard to find a place to live but it's no use" $(r=-.42, p<.01)$. The latter statement was one of the four helplessness index items. Stability attributions were not significantly correlated with any of the helplessness items or the helplessness index.

\section{Hypothesis 3}

Hypothesis 3 predicted that low-control environments would be correlated with the external, stable attributional pattern characteristic of universal helplessness. This hypothesis was partially supported. Low perceived control in the shelter environment was not significantly correlated with an external attributional pattern. However, it was significantly correlated with stability attributions $(r=.36, p<$ .05). In other words, perceiving low control in the shelter environment was positively correlated with feeling that the causes of negative life events were unlikely to change.

\section{Hypothesis 4}

Hypothesis 4 predicted that individuals who had a history of depression prior to homelessness would be more likely to exhibit the internal, stable, 
global attributional style characteristic of personal helplessness than those who reported no prior history of depression.

An independent samples t-test comparing respondents who reported being depressed prior to homelessness $(n=13)$ with respondents who said they were not $(n=18)$ on internal attributional style found that those previously depressed were significantly more likely to display an internal attributional style $(\mathrm{t}(29)=-2.5, p<.01)$. The two groups did not differ significantly on stability attribution scores $(\mathrm{t}(27)=-1.22, p<.05)$ but did differ significantly on globality scores $(\mathrm{t}(25)=-2.28, p<.05)$, with those depressed prior to homelessness more likely to make global attributions. The two groups also differed significantly on the Beck, with the depressed-prior-to-homelessness group scoring higher $(\mathrm{t}(34)=-2.12$, $p<.05)$. The two groups did not differ significantly on agreement with statements about giving up on finding a home or a job $(\mathrm{t}(36)=1.66, p>.05)$.

\section{Discussion}

A significant relationship between perceived loss of control and helplessness was found. This suggests that effectively helping the homeless may involve carefully designing the organizations and environments intended to help them, since shelters and service organizations with rigid rules and little privacy may increase helplessness and passivity. However, while the study findings suggest that rule rigidity should be minimized, this is not to say that there should be a complete lack of structure since some structure provides a predictability that may reduce stress and increase control. As pointed out by Barnes (1981), Glass and Singer's (1972) work found that greater control is experienced under conditions of high predictability.

Loss of privacy was one of the strongest predictors of helplessness found by the study. Since privacy has important implications for identity, perceived control, and passivity, Altman (1975) suggests "responsive" environments should be created. Such environments permit easy alternation between separateness and togetherness. Simple architectural interventions to increase privacy in the shelter environment, such as curtains or screens between cots, should be examined.

Several things should be considered that affect the feasibility of altering the shelter environment. One of these is the fact that staff prefer a highly structured environment since it reduces their stress and for this reason they may be reluctant to reduce rule rigidity. Second, people who are not used to having control may not exert control even when it is available. Studies of crowding and personal control by Baum et al. (1981) found that severe and prolonged decrements in control have a negative influence on expectations of control in future situations. This means that homeless people will need a lot of encouragement and guidance to get them to try again. Conversely, they need experiences which empower them and do not further contribute to their helplessness by taking away all personal control.

It was expected that external, stable attributions would be correlated with helplessness and lowcontrol environments. It seems plausible that environments that are consistently low in control would lead to external, stable attributions, and "universal" helplessness. External attributions were marginally correlated with helplessness, stability attributions were not. Furthermore, perceived control was correlated with stability attributions but not with an external attributional pattern. One explanation for these weak results is that only loss of control in the current shelter environment was measured, whereas 
attributional style may be a relatively stable trait developed over a long period of time. For the lowincome individual or homeless person, universal helplessness may be a product of exposure to a long series of low-control environments.

Consistent with earlier research (Peterson \& Seligman, 1984), those who evidenced clinical depression were more likely to exhibit an internal, global attributional style. However, this group did not differ significantly on stability attributions from the nondepressed group. The two groups also did not differ significantly on helplessness. Because helping environments may influence expectancies regarding control, helping environments where occupants have a say in what happens to them are probably desirable regardless of attributional style. However, because of their low self-esteem, the alleviation of passivity in the clinically depressed homeless (those with longer term depressions) will probably require mental health care as well.

It should be pointed out that changes in the shelter environment are unlikely to be enough to eliminate passivity in the homeless, since perceptions of noncontingency are likely to persist as long as low income housing is difficult to obtain. Unfortunately, because of cuts in social services, economic recession, and landlord prejudice, homeless individuals' attempts to change their situations may make little difference. Consequently, convincing individuals in poverty that their outcomes are contingent upon their actions may require increases in social services and affordable housing.

The study described here has several notable shortcomings. First, because of the correlational nature of the study, causal conclusions are difficult to assert. For instance, results supported the hypothesis that perceived loss of control over the shelter environment would be positively correlated with helplessness. This could mean that helplessness makes individuals more likely to perceive environments as low in control or that low-control environments lead to helplessness. Both propositions have received some research support and are by no means mutually exclusive. Previous research has established that persons exposed to uncontrollable sources of environmental stress suffer from helplessness (e.g., Baum, Fleming, \& Reddy, 1986; Baum \& Paulus, 1987; Cohen, et al., 1986) and that decrements in control can influence expectations of control in future situations (Baum et al., 1981). Ideally, field experiments should be used to compare residents of shelters low in control with those from shelters high in control on multiple measures of outcome (apathy, success in finding a home, stress, self-esteem, etc.). Quasi-experiments comparing occupants of shelters rated on the amount of control may be more feasible, though lower in internal validity. Perhaps even more constructive would be for future researchers to test interventions designed to increase privacy and control in the shelter environment.

Another problem with the study centers around the small sample size, which did not permit analysis by gender or ethnicity and limits generalizability. The fact that only one shelter was studied also poses a problem for generalizability and it should also be noted that the sample did not include the mentally ill homeless.

In closing, it appears that before we can realistically expect homeless people to keep trying to change their life situations, we may need to change the design of homeless shelters and increase the probability that their efforts to find housing and employment will be successful. In addition, we should not overlook the social and environmental origins of explanatory styles. We need to recognize that the treatment of 
certain population subgroups can produce or exacerbate helplessness, negative explanatory styles, and psychological distress.

\section{References}

Abramson, L. Y., Garber, J., \& Seligman, M. E. P. (1980). Learned helplessness in humans: An attributional analysis. In J. Garber \& M. E. P. Seligman (Eds.), Human helplessness: Theory and applications (pp. 3-34). New York: Academic Press. Abramson, L. Y., Seligman, M. E. P., \& Teasdale, J. D. (1978). Learned helplessness in humans: Critique and reformulation. Journal of Abnormal Psychology, 87, 49-74.

Altman, I. (1975). The environment and social behavior. Monterey, CA: Brooks-Cole.

Altman, I., \& Chemers, M. (1980). Culture and environment. Belmont, CA: Wadsworth.

Barnes, R. D. (1981). Perceived freedom and control in the built environment. In J. H. Harvey (Ed.), Cognition, social behavior and the environment (pp. 409-422). Hillsdale, NJ: Erlbaum.

Baum, A., Fleming, R., \& Reddy, D. M. (1986). Unemployment stress: Loss of control, reactance, and learned helplessness. Social Science and Medicine, 22, 509-516.

Baum, A., \& Gatchel, R. J. (1980). Locus of control and learned helplessness. Unpublished manuscript.

Baum, A., Gatchel, R. J., Aiello, J. R., \& Thompson, D. (1981). Cognitive mediation of environmental stress. In J. H. Harvey (Ed.), Cognition, social behavior, and the environment (pp. 513-534). Hillsdale, NJ: Erlbaum.

Baum, A., \& Paulus, P. (1987). Crowding. In D. Stokols \& I. Altman (Eds.), Handbook of environmental psychology (pp. 533-570). New York: Wiley.

Beck, A. T., Rush, A. J., Shaw, B. F., \& Emery, G. (1979). Cognitive therapy of depression. New York: Guilford.

Beck, A. T., \& Beck, R. W. (1972). Screening depressed patients in family practice: A rapid technique. Postgraduate Medicine, 52, 81-85.

Cohen, S., Evans, G. W., Stokols, D., \& Krantz, D. S. (1986). Behavior, health, and environmental stress. New York: Plenum.

Dweck, C. S., \& Goetz, T. E. (1978). Attribution and learned helplessness. In J. H. Harvey, W. Ickes, \& R. F. Kidd (Eds.), New directions in attribution research (Vol. 2). Hillsdale, NJ: Erlbaum.

Dweck, C. S., \& Licht, B. G. (1980). Learned helplessness and intellectual achievement. In J. Garber \& M. E. P. Seligman (Eds.), Human helplessness: Theory and applications (pp. 197-222). New York: Academic Press.

Dweck, C. S., \& Repucci, N. D. (1973). Learned helplessness and reinforcement responsibility in children. Journal of Personality and Social Psychology, 25, 109-116.

Glass, D. C., \& Singer, J. E. (1972). Behavioral aftereffects of unpredictable and uncontrollable events. American Scientist, 80, 457-465.

Hanusa, B. H., \& Schulz, R. (1977). Attributional mediators of learned helplessness. Journal of Personality and Social Psychology, 77, 602-611.

Langer, E. J., \& Rodin, J. (1976). The effects of choice and enhanced personal responsibility for the aged: A field experiment in an institutionalized setting. Journal of Personality and Social Psychology, 37, 20032013.

Peterson, C., \& Seligman, M. E. P. (1984). Causal explanations as a risk factor for depression: Theory and evidence. Psychological Review, 91, 347-374.

Peterson, C., \& Villanova, P. (1988). An expanded attributional style questionnaire. Journal of Abnormal Psychology, 97, 87-89.

Proshansky, H. M., Ittelson, W. H., \& Rivlin, L. G. (1970). The influence of the physical environment on behavior: Some basic assumptions. In $\mathrm{H}$.

Proshansky, W. Ittelson, \& L. Rivlin (Eds.), Environmental psychology (Vol. 1, pp. 27-37). New York: Holt, Rinehart, \& Winston.

Redburn, F. S., \& Buss, T. F. (1986). Responding to America's homeless: Public policy alternatives. New York: Praeger.

Rodin, J. (1976). Crowding, perceived choice, and response to controllable and uncontrollable outcomes. Journal of Experimental Social Psychology, 12, 564-578.

Wortman, C. B., Panciera, L., Shusterman, L., \& Hibscher, J. R. (1976). Attributions of causality and reactions to uncontrollable outcomes. Journal of Experimental and Social Psychology, 12, 301-316. 
Table 1

Control and Helplessness Correlations

\begin{tabular}{|c|c|c|c|c|c|c|c|}
\hline \multirow[b]{2}{*}{ Helplessness items } & \multicolumn{7}{|c|}{ Control items } \\
\hline & Privacy & Crowd & Freedom & Eat $^{\mathrm{a}}$ & Sleep $\mathrm{I}^{\mathrm{b}}$ & Sleep2 ${ }^{c}$ & $\begin{array}{l}\text { Control } \\
\text { Index }\end{array}$ \\
\hline 1. No use trying to find housing I can afford & $.28^{*}$ & $.36 * *$ & .23 & $.32^{*}$ & .09 & .11 & $.38 * *$ \\
\hline 2. I have given up trying to find a job & .19 & .05 & $.27^{*}$ & .18 & .16 & .10 & $.27 *$ \\
\hline $\begin{array}{l}\text { 3. If I try hard enough I will find a place to } \\
\text { live (scoring reversed) }\end{array}$ & $.29 *$ & .01 & $.28^{*}$ & .03 & .05 & .18 & .14 \\
\hline $\begin{array}{l}\text { 4. I have tried hard to find a place to live but } \\
\text { it's no use }\end{array}$ & $.29 * *$ & $.44 * *$ & .23 & .03 & .01 & $.30^{*}$ & $.35^{* *}$ \\
\hline Helplessness index & $.34^{* *}$ & $.29^{*}$ & $.33^{* *}$ & .17 & .09 & .11 & $.37 * *$ \\
\hline
\end{tabular}

Note. All items were rated using a 7-point Likert scale where high numbers indicated agreement with statements suggesting low control and high helplessness.

a"Eat" represents agreement with the statement "I have no choice about when I eat." b"Sleepl" represents agreement with the statement "I have no choice about when to sleep." "Sleep2" represents agreement with the statement "I have no choice about where to sleep."

${ }^{*} p<.05,{ }^{* *} p<.01$. 